The Effects of Regional Climate Change on Space Conditioning Needs and the Energy Industry in the Great Lakes Region

\author{
Mark E. Fernau" \\ Eric D. Maloney
}

Technology and Environmental Policy Section

Argonne National Laboratory

EID/900 9700 South Cass Ave., Argonne, Illinois 60439 U.S.A.

\title{
Gary T. Bates
}

National Center for Atmospheric Research"*

P.O. Box 3000, Boulder, Colorado 80307 U.S.A.

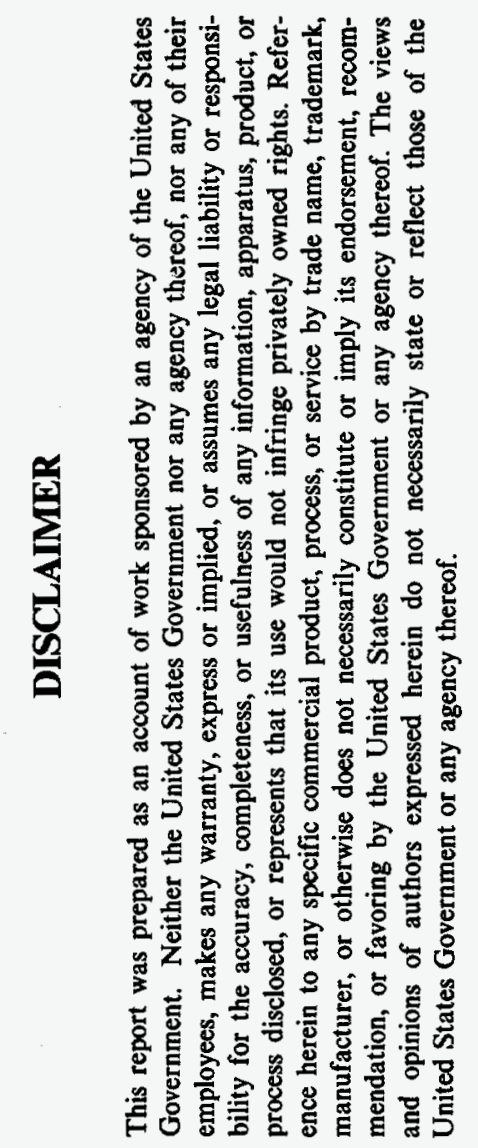

"The National Center for Atmospheric Research is sponsored by the U.S.A. National Science Foundation

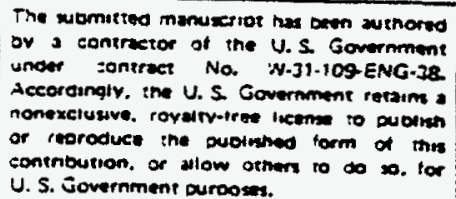

'Present address of corresponding author:

Sigma Research Corporation

196 Baker Avenue

Concord. MA 01742 


\section{Abstract}

To date, studies of the effects of potential climate change on energy use and demand have been done on a macro scale or with coarse model data but it is regional climate change effects that will determine the behavior of energy users. The output from a 3-year simulation (both base case and doubled $\mathrm{CO}_{2}$ conditions) of the coupled NCAR CCM/MM4 regional (60 km resolution) climate modeling system is used to examine changes in average temperature and temperature variability on a regional scale, the impacts of such change on the need for space conditioning in the Great Lakes region, and the subsequent changes in energy demand. From these results, changes in heating and cooling degree days, and changes in consecutive days above or below various temperature thresholds were calculated. The model results indicate that the changed climate under doubled carbon dioxide conditions would have large impacts on energy use, although it is difficult to determine the balance between decreased heating needs and increased cooling needs. Biases are present in the temperature output of the modeling system. However, the model shows promise for regional studies and the recent successful coupling of a one-dimensional thermal eddy diffusion model to the NCAR modeling system to represent the Great Lakes promises that the next iteration of climate change output from the NCAR system will yield important results when applied to effects studies.

\section{Introduction}

The enhancement of the atmospheric greenhouse effect by anthropogenic emissions of carbon dioxide, methane, chlorotluorocarbons and other gases is predicted by general circulation models (GCMs) to lead to changes in world climate (Houghton et al, 1990). However, policy makers must be confident that they understand the likely effects of climate change on the regional scale that is of interest to their constituents before they will commit significant resources to mitigating potential climate change (Science and Policy Associates Inc.. 1992). Effects studies that try to determine 
regional scale impacts of climate change have been hampered by the poor spatial resolution ( 400 to $1000 \mathrm{~km}$ ) of the general circulation models on which the climate change used in the studies is based (Smith and Tirpak. 1989; Takle and Zhong, 1991). Because of the uncertain nature of these studies, policy makers so far have been reluctant to commit the United States to a large scale mitigation effort.

In this study, a new set of model results with much improved resolution is used to illustrate that output from a mesoscale model driven by GCM output potentially can yield useful climate change information on a regional basis for use until that time when improved computer technology makes possible the running of general circulation models at high resolution. Modelers at the National Center for Atmospheric Research (NCAR) have developed a modeling system in which a limited area mesoscale model (the NCAR/Penn State Mesoscale Model, Version IV [MM4]) is run for extended simulation periods (months to years) with a grid cell size of 100 kilometers or less to yield a regional climate (Dickinson et al, 1989). MM4 has been modified to incorporate a GCMcompatible radiative transfer scheme, an improved boundary layer parameterization and a surface physics/soil hydrology package known as the Biosphere Atmosphere Transfer Scheme (BATS). The initial and boundary conditions for the mesoscale model are provided either by gridded observation data or by the output from a GCM. If the GCM output is from a future climate scenario, then climate change scenarios that are based on the large scale circulation changes but that incorporate regional scale features and effects can be generated with the modeling system. Output from this modeling system is used to examine potential effects of climate change on energy demand in the Great Lakes region. 


\section{Description of the Data Set}

The NCAR regional climate modeling system is the first instance in which a mesoscale weather prediction model has been run without reinitialization for an extended simulation period of months or years. Its output has been compared extensively against the observations and the output from the GCMs that are used to drive the model. The results show that when driven by observations the model system produces a realistic climate and that when driven by GCM output it retains the large scale circulation information from the GCM but captures much more realistically the influences on climate of smaller scale features such as complex terrain and water bodies (Giorgi et al, 1993a; Giorgi et aL,1993b; and additional references cited in these two papers). Giorgi et al (1993a) conclude that "[t]his work shows that it is feasible to perform good quality, multiyear simulations with current limited-area models and, therefore, that it is feasible to apply such models to climate studies." Giorgi et aL (1993b) state that "[t]his work illustrates the feasibility of the nested modeling technique to long term regional climate simulation" and that because of differences in predicted climate between the GCMs and the limited area models "cautious use should be made of direct GCM output for impact assessments."

Giorgi et al (1993b) used the NCAR regional climate modeling system to produce two three-year simulations of the climate over the United States, at a 60 kilometer resolution. One simulation used a present-day atmospheric carbon dioxide $\left(\mathrm{CO}_{2}\right)$ concentration of 340 ppmv and the other used a value of 680 ppmv carbon dioxide to represent a doubled $\mathrm{CO}_{2}$ scenario. Both cases were driven by the last three years of 24-year climate simulations of a version of the NCAR Community Climate Model GCM that is known as GENESIS and is described in Giorgi et aL (1993b). GENESIS has a horizontal grid spacing of $4.5^{\circ} \times 7.5^{\circ}$ and is coupled to a 50 -meter mixed layer ocean model. It has an enhanced surface physics package that is similar to BATS and has a $2^{\circ}$ by $2^{\circ}$ resolution. 
GENESIS represents the Great Lakes by three data points; MM4 uses 64 grid cells to represent the Great Lakes.

Giorgi et al (1993b) found that the average daily air temperature at 40 meters for the current climate simulation using MM4 driven by GENESIS had an overall bias for the United States of + $1.1{ }^{\circ} \mathrm{C}$ (overprediction) in the five coldest months and $-0.7^{\circ} \mathrm{C}$ (underprediction) for the five warmest months, but the corresponding biases for the Great Lakes region were $+6.2^{\circ} \mathrm{C}$ and +3.9 ${ }^{\circ} \mathrm{C}$, respectively. Thus, in the Great Lakes region, the modeling system overpredicts temperatures by about $5^{\circ} \mathrm{C}$. A similar bias is present in the GENESIS output. Apparently, the increased resolution in the Great Lakes area compared to that in the driving GCM is not sufficient to eliminate the bias that is present in the GCM. However, MM4 did moderate temperatures in the vicinity of the lakes, compared to GENESIS, and predicted about $1{ }^{\circ} \mathrm{C}$ less warming in the Great Lakes under doubled $\mathrm{CO}_{2}$ compared to GENESIS predictions. In Giorgi et al (1993b), the relatively short three-year 40 -meter simulated temperatures are compared to observed long term normal surface temperatures. It is possible that with a longer MM4 simulation a different bias might be obtained.

Recently, Bates et al. (1993) demonstrated a successful coupling of a one-dimensional thermal eddy diffusion model to the NCAR modeling system to represent the Great Lakes. The output gave more realistic behavior for Lake temperatures and it is planned to generate new U.S. climate simulations for present day and doubled carbon dioxide conditions using MM4 with the lake model incorporated. In addition, improvements have been made to the driving GCM. These simulations should yield a much reduced bias in the Great Lakes temperature field. When this output is available, the analysis performed in this paper will be repeated. 


\section{Methods}

The current day (denoted $1 \mathrm{XCO} 2$ ) and the doubled carbon dioxide (2XCO2) MM4 simulations of Giorgi et al (1993b) were used as the starting point for this analysis. The daily maximum and minimum temperatures at 40 meters above ground level and in the air within the vegetation canopy foliage were extracted for a region encompassing the Great Lakes (Figure 1) and were converted to a surface air temperature using the following approximation (Dickinson et al, 1986; Giorgi et al, 1993a):

$$
T_{a}=T_{f}+0.55\left(T_{m}-T_{f}\right)
$$

where $T_{a}$ is the surface air temperature, $T_{f}$ is the vegetation canopy air temperature and $T_{m}$ is the temperature at the lowest model level. Some uncertainty is introduced at this step because daily maxima and minima were used in place of hourly temperatures and the values in the canopy and lowest level could occur at different hours. If no vegetation is present the canopy temperature is set to the ground air temperature.

Using the derived surface air temperatures, the maximum and minimum daily surface temperatures were averaged to produce a daily mean temperature. This value was used to compute heating degree days, cooling degree days, and the difference in degree days between the control case and the doubled $\mathrm{CO}_{2}$ case. The degree days were based on the common base of $65^{\circ} \mathrm{F}$ used by utilities, engineers and the National Weather Service. 


\section{Resuits}

For this study, twelve locations in the vicinity of the Great Lakes were selected for further analysis. These locations include Buffalo, New York; Midway and O'Hare airports in Chicago, Illinois; Cleveland, Ohio; Des Moines, Iowa; City and Metro airports near Detroit, Michigan; Milwaukee, Wisconsin; Toronto, Ontario; and Rockford, Springfield and Urbana in Illinois. Observed monthly temperature and degree day data were obtained for these locations from National Weather Service data or other sources. For this study, maximum and minimum temperature data were obtained only for January, April, July and October for Toronto and no Toronto degree data were obtained. No degree day data were obtained for Urbana. Climate normals were based on 1951 to 1980 except for Detroit City and Chicago Midway airports which were based on 1941 to 1970 and Urbana, which was based on 1951 to 1973 . It was not known for which years the Toronto averages applied.

The model grid cell nearest to each location was determined using latitudes and longitudes and was used for comparison to observations. Several interpolation schemes were examined but because of large differences in simulated temperature between the lakes and land in the vicinity of several locations these yielded poor results. For instance, Rockford and Chicago O'Hare are located close to each other at about the same latitude and their observed annual mean heating degree days only differ by about seven percent, but when an interpolation of the $1 \mathrm{XCO} 2$ case is done using the four closest grid cells, the simulated heating degree days differ by over twenty percent. The reason is that the modeled Rockford value is based on four land grid cells, while the Chicago value is interpolated from both land and water cells. For this reason, the simulated values from the nearest grid cell were used for comparison to observations. In addition, for the Chicago O'Hare site the second closest grid point was used. because the closest cell was located over Lake Michigan and compared poorly to observations. Figure 1 shows which grid points were used for each location. 
For the $1 \mathrm{XCO} 2$ case, the daily maxima and minima associated with the twelve locations were used to obtain monthly mean maximum, minimum and average temperature for each of the available 36 months. From these the monthly and annual three-year averages were calculated. These were then compared to the observed monthly averages at each location. Since only three years were simulated, there will be less variability in the predicted values than in the observations. The temperatures were converted to degrees Fahrenheit and. will be presented that way in this paper because that is the unit for which heating degree days and cooling degree days are calculated in the United States.

The effect of the lakes is evident in the simulated monthly temperature averages. Figures 2 and 3 show the average temperatures for December through February and June through August for the $\frac{F \div}{\vdots} \div$ $1 \mathrm{XCO} 2$ run. The contours follow the lakes closely.

The bias discussed by Giorgi et al. (1993b) for the Great Lakes region was obvious in the $1 \mathrm{XCO} 2$ model results. The bias in the maximum, minimum and average annual and monthly mean temperatures was calculated by comparing the model results with the observations. Over the twelve locations, the modeled maximum temperature averaged $4.7^{\circ} \mathrm{F}$ above observations, the minima averaged $6.7^{\circ} \mathrm{F}$ too warm, and the average temperature was $5.7^{\circ} \mathrm{F}$ too warm. The largest biases appeared in the summer months for maximum temperatures. The least bias, at times even negative, appeared in the spring months for minimum temperatures. Figure 4 shows the monthly mean observed and simulated temperatures tor Miidway airport in Chicago to illustrate the bias. This bias leads to annual heating and cooling degree days for the $1 \mathrm{XCO} 2$ simulation that also are biased. For instance, the heating degree days for Midway are too low by fifteen percent and the cooling degree days are too high by 50 percent. 
Because of the large bias in the Great Lakes simulated temperatures, the absolute numbers for the two MM4 runs cannot be used for the energy analysis. It is common when doing climate change effects studies to add the simulated change in temperature to the observed normals for the areas of interest to overcome inaccuracies in the base case. However, since degree days are anchored to a fixed temperature, the change in degree days between the $1 \mathrm{XCO} 2$ and $2 \mathrm{XCO} 2$ scenarios also is likely to be biased. The approach taken in this study was to subtract the monthly biases in the maximum and minimum temperature at each location from the simulated daily maxima and minima before calculating daily degree days and the changes in degree days between scenarios. For Toronto, the two months surrounding the mid-season month were assigned the bias corresponding to the mid-season month. Application of this method removed the bias from the $1 \mathrm{XCO} 2$ temperatures, leading to adjusted monthly mean temperatures and degree days at each location that were almost identical to the observed means.

The changes in annual heating and cooling degree days at each location that results after the biases are removed from both the $1 \mathrm{XCO} 2$ and $2 \mathrm{XCO} 2$ data sets are shown in Figures 5 and 6 , respectively. Heating degree day changes were very consistent from site to site, with the decrease varying from 31 to 34 percent. Under $2 \mathrm{XCO} 2$ conditions, heating degree days have disappeared entirely during July and August and dwindled to almost none in June and September. Cooling degree days increase substantially in the $2 \mathrm{XCO} 2$ simulation. All locations but Des Moines, Springfield and Urbana increase by 100 percent or more, with Buffalo and Milwaukee increasing by over 160 percent. Toronto almost triples, but this is probably an artifact of the way that the bias was assigned for that location. The spring and autumn biases at Toronto are very large compared to the other sites and these are assigned to all three months. The transition months of April. May, 
September and October have substantially more cooling degree days at each site under doubled $\mathrm{CO}_{2}$ conditions.

After adjusting for the model bias, the occurrence and frequency of temperature extremes was examined. The dates of first and last freezes, defined as the last day of winter or spring and the first day of autumn or winter with a minimum below $32^{\circ} \mathrm{F}$, were determined for the various locations (all but Detroit City and Chicago Midway) under the two scenarios. The effect of doubling $\mathrm{CO}_{2}$ was to extend the frost-free period for almost all years and sites. The changes ranged from shrinking by one day to extending by 104 days the number of annual days between freezes. Urbana averaged an 83-day extension for the three years while Milwaukee only averaged 17 . Most sites averaged one to two months more frost-free days. There was substantial year to year variation; Milwaukee's average of 17 consisted of a shrinkage of one day and extensions of six and 45 days and the extension at Chicago O'Hare varied from seven to 57 days.

Changes in extremely warm days were examined at three sites (Table I). The period between the first and last occurrence of temperatures $90^{\circ} \mathrm{F}$ and above increased by an average of three to five weeks, with a range from a decrease of eleven days to an increase of seven weeks, for the three simulated years with a doubling of $\mathrm{CO}_{2}$. Under $2 \mathrm{XCO} 2$ conditions, the first occurrence of temperatures at $95^{\circ} \mathrm{F}$ or above for the three sites shifted into late May or early to mid June from July and the last occurrence usuaily shifted from July or August into September. The average number of days at or above $90^{\circ} \mathrm{F}$ increased by 32 at $\mathrm{O}^{\prime} \mathrm{Hare}, 38$ at Des Moines and 32 at Urbana. The average number of days at or above $95^{\circ} \mathrm{F}$ increased by 15 at $\mathrm{O}^{\prime} \mathrm{Hare}, 20$ at Des Moines and 14 at Urbana. 
Consecutive day runs of extreme temperatures increased substantially at the three sites. For the control run. O'Hare only had one instance of two consecutive days at or above $95^{\circ} \mathrm{F}$. Under $2 \mathrm{XCO} 2$, there were four instances of two consecutive days, two instances of three days, one instance of four days, two instances of five days and one instance of six consecutive days at or above $95^{\circ} \mathrm{F}$. Ninety ${ }^{\circ} \mathrm{F}$ temperatures at $\mathrm{O}^{\prime} \mathrm{Hare}$ never occurred more than five days in a row under $1 \mathrm{XCO} 2$. There were seven instances of at least five consecutive days of $90^{\circ} \mathrm{F}$ or above under $2 \mathrm{XCO} 2$, one of which lasted for 25 consecutive days! Similar resuits were found for Des Moines and Urbana, with the number of long temperature runs increasing substantially. Under 2XCO2, Des Moines had one run of ten consecutive days at or above $95^{\circ} \mathrm{F}$ and runs of 16,13 and 21 days in a row at or above $90^{\circ} \mathrm{F}$. Urbana went from no runs of three or more days of $95^{\circ} \mathrm{F}$ to eight runs at this threshold, the longest lasting six days.

\section{Discussion}

This paper presents a first use of simulated regional climate change from a limited area model driven by a general circulation model to examine changes in degree days and temperature extremes on a regional scale. Because of uncertainties present in the driving GCM and the simple fashion in which the Great Lakes are portrayed in both models, the quantitative results presented here must be considered as preliminary and as an example of the analysis that can be conducted with the coupled modeling approach as technical improvements reduce the model bias. Until GCMs can achieve a resolution of less than one hundred kilometers, the coupled approach with improved GCM input and an improved treatment of the Great Lakes is a viable substitute approach for providing interim guidance to policy makers who must grapple with decisions regarding the mitigation of potential climate change and its impacts on energy demand and other areas. 
Studies (Smith and Tirpak. 1989; Linder et al. 1989) that used low resolution output from GCMs to drive energy demand models have suggested that trace gas-induced climate change could have major impacts on energy demand and peak capacity requirements of utilities. Increased air conditioning will require additional energy during the warmest periods. In more northerly areas this will be offset to a minor or major extent by decreased heating needs.

The qualitative trends described in this paper, derived from the more highly resolved coupled modeling system, support this conclusion and point out the potential magnitude of the problem over the next century. The 30 percent decrease in heating degree days in the Great Lakes region with $2 \mathrm{XCO} 2$ implies a decrease in heating needs of similar magnitude (Blair, 1992). There is less agreement on the relationship between cooling degree days and fuel use, because it depends also on humidity and the degree to which people will tolerate warmer weather. However, the doubling of cooling degree days and the large increase in the number and persistence of very warm days under $2 \mathrm{XCO} 2$ suggest that growth in energy demand for summer air conditioning may be larger than the reduction in energy use that will result from lowered heating needs in the Great Lakes region and surrounding areas. The disparity in the magnitudes of these two trends suggest that this result likely will be upheld when results from the improved NCAR regional climate modeling system become available.

Sebold and Parris (1989) derived regression equations that relate residential end-use unit energy consumption to heating and cooling degree days for conventional space heating and conventional central air conditioning, respectively. Application of these relationships to O'Hare and Urbana gives the result that unit energy consumption for space conditioning actually will decrease by about 2000 kilowatt hours per year per residential dwelling at these two locations under 2XCO2 
conditions, contradicting the above intuitive result. However, these relationships contain considerable uncertainty, expressed as scatter about the regression line, are based on a limited sample and do not consider commercial changes. Thus, it is difficult to ascertain their accuracy.

Regardless of whether the impact on energy use is positive or negative, the NCAR regional climate modeling system predicts large changes in temperatures and thus degree days under doubled $\mathrm{CO}_{2}$ conditions. It is unlikely that energy demand will be unaffected if such conditions come to pass. The concept of using a mesoscale model driven by a general circulation model to simulate climate has been tested rigorously and yields useful insights into the potential impacts of climate change on a regional scale. These insights will be revisited and improved in further work as more sophisticated versions of the modeling system are implemented.

\section{Acknowledgment}

Work supported by the U.S. Department of Energy under contract W-31-109-Eng-38.

\section{References}

Bates, G. T., Giorgi, F., and Hostetler, S. W.: 1993, 'Toward the Simulation of the Effects of the Great Lakes on Regional Climate', Mon. Weather Rev. 121, 1373-1387.

Blair, F. E. (ed.): 1992. The Weather Almanac, Gale Research, Detroit.

Dickinson, R. E., Kennedy, P. J., Henderson-Sellers, A., and Wilson, M.: 1986, BiosphereAtmosphere Transfer Scheme (BATS) for the NCAR Community Climate Model. NCAR/TN275+STR, National Center for Atmospheric Research, Boulder, CO. 
Dickinson, R. E., Errico, R. M., Giorgi, F., and Bates, G. T.: 1989, 'A Regional Climate Model for the Western United States', Clim. Change 15, 383-422.

Giorgi, F., Bates, G. T., and Nieman, S. J.: 1993a, 'The Multiyear Surface Climatology of a Regional Atmospheric Model Over the Western United States', J. Climate 6, 75-95.

Giorgi, F., Shields Brodeur, C., and Bates, G. T.: 1993b, 'Regional Climate Change Scenarios Over the United States Produced with a Nested Regional Climate Model: Spatial and Seasonal Characteristics', J. Climate, accepted for publication.

Houghton, J. T., Jenkins, G. J., and Ephraums, J. J. (eds.): 1990, Climate Change, The Scientific Assessment; Report to the Intergovernmental Panel on Climate Change, Cambridge University Press, Cambridge.

Linder, K. P., Gibbs, M. J., and Inglis, M. R.: 1989, Potential Impacts of Climate Change on Electric Utilities, Report No. EN-6249, Electric Power Research Institute, Palo Alto, CA.

Science and Policy Associates: 1992, Joint Climate Project to Address Decision Makers Uncertainties, Report of Findings, May 1992, Report No. TR-100772, Available from Electric Power Research Institute Distribution Center, Pleasant Hill, CA.

Sebold, F. D. and Parris, K. M.: 1989, Residential End-Use Energy Consumption: A Survey of Conditional Demand Estimates, Report No. CU-6487, Electric Power Research Institute, Palo Alto, CA. 
Smith, J. B., and Tirpak, D. (eds.): 1989, The Potential Effects of Global Climate Change on the United States: Report to Congress, EPA-230-05-89-050, United States Environmental Protection Agency Office of Policy, Planning and Evaluation, Washington, DC.

Takle, E. S., and Zhong, S.: 1991, 'Towa's Climate as Projected by the Global Climate Model of the Goddard Institute for Space Studies for a Doubling of Atmospheric Carbon Dioxide', J. Iowa Acad Sci. 98(4), 153-158. 
Fig. 1. Grid point resolution of the NCAR regional climate modeling system used in this study. The starred points correspond to the points used to analyze climate change at major cities in the Great Lakes region.

Fig. 2. Average temperatures in degrees Fahrenheit for winter (December, January and February) for the 3-year control simulation using MM4 driven by a general circulation model. The influence of the lakes clearly is evident in the contour pattern.

Fig. 3. As in Figure 2, but for summer (June, July and August).

Fig. 4. Monthly mean maximum (MAX), minimum (MIN) and average (AVG) temperatures for observed temperatures (dark shapes) and simulated base case temperatures (open shapes) at Chicago Midway Airport. The warm bias in the simulated temperatures is evident.

Fig. 5. Change in 3-year annual average hiciting degree days at selected locations in the Great Lakes region between doubled $\mathrm{CO}_{2}$ conditions $(2 \mathrm{XCO} 2)$ and present day conditions (1XCO2), as simulated by MM4.

Fig. 6. Change in 3-year annual average cooling degree days at selected locations in the Great Lakes region between doubled $\mathrm{CO}_{2}$ conditions $(2 \mathrm{XCO} 2)$ and present day conditions (1XCO2), as simulated by MM4. 
Table I. Changes in extremely warm days at three locations between doubled $\mathrm{CO}_{2}$ conditions (2XCO2) and present day conditions (1XCO2), as simulated by MM4. Change Range 90 denotes the change in the length of the period between the first and last occurrence of temperatures $90^{\circ} \mathrm{F}$ and above, in days. Change Days 90 and Change Days 95 denote the change in the total number of days at or above $90^{\circ} \mathrm{F}$ and $95^{\circ} \mathrm{F}$, respectively.

\begin{tabular}{||l|c|c|c|}
\hline & Change Range 90 & Change Days 90 & Change Days 95 \\
\hline O'Hare Year 1 & 30 & 50 & 17 \\
\hline O'Hare Year 2 & 37 & 31 & 13 \\
\hline O'Hare Year 3 & 6 & 15 & 12 \\
\hline Des Moines Year 1 & 49 & 37 & 22 \\
\hline Des Moines Year 2 & 19 & 48 & 13 \\
\hline Des Moines Year 3 & -11 & 30 & 13 \\
\hline Urbana Year 1 & 47 & 37 & 22 \\
\hline Urbana Year 2 & 23 & 35 & 13 \\
\hline
\end{tabular}




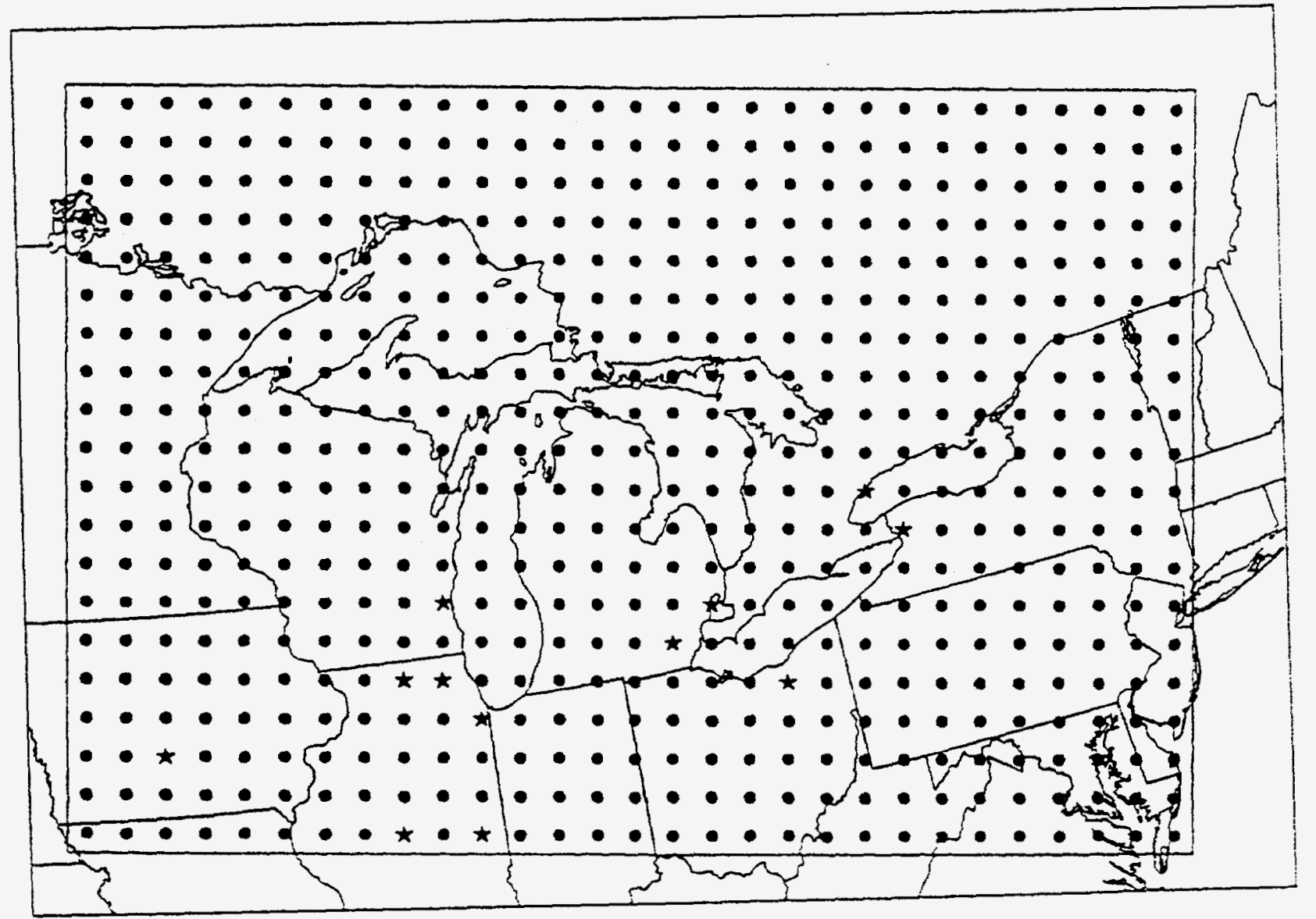




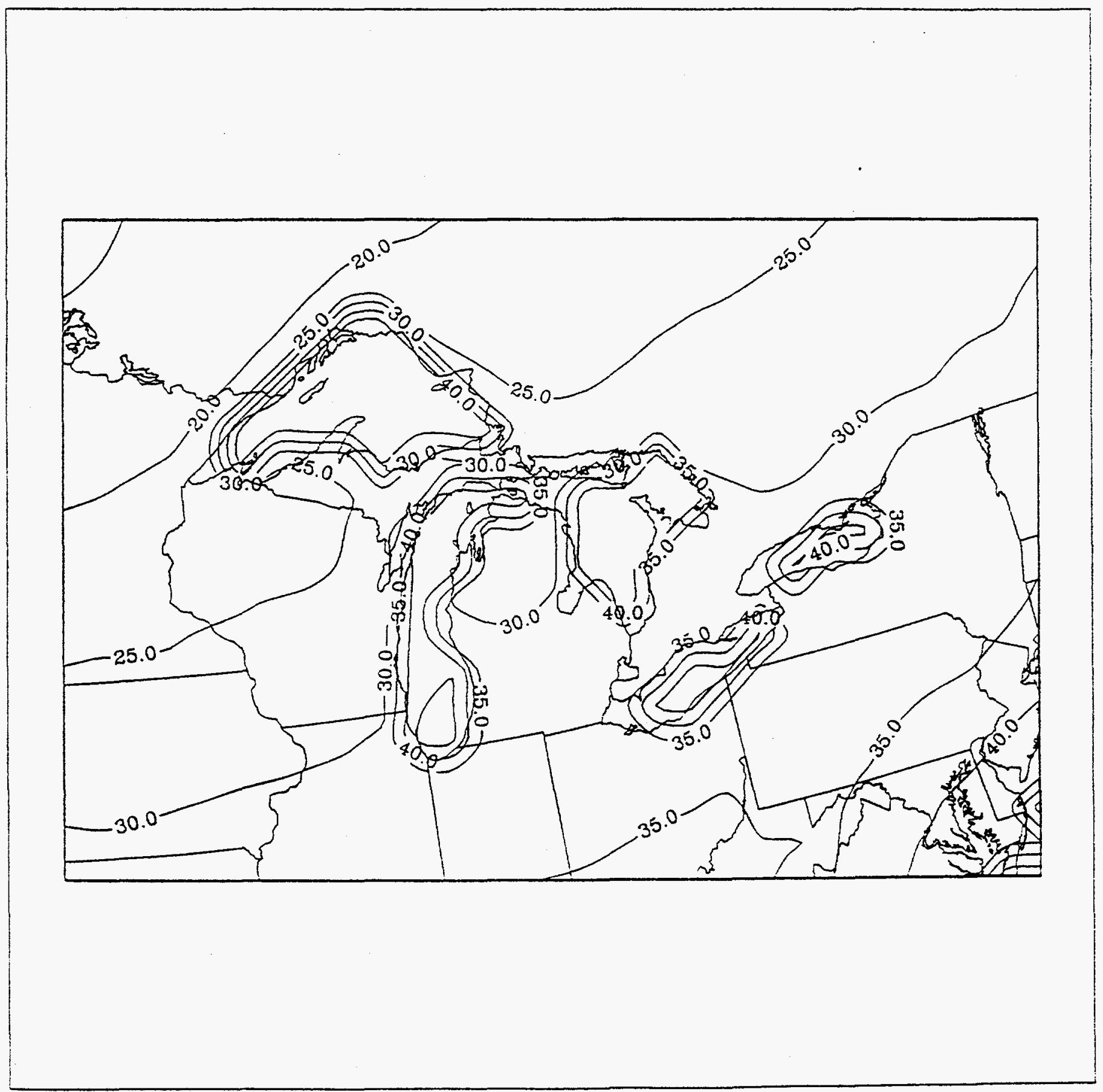




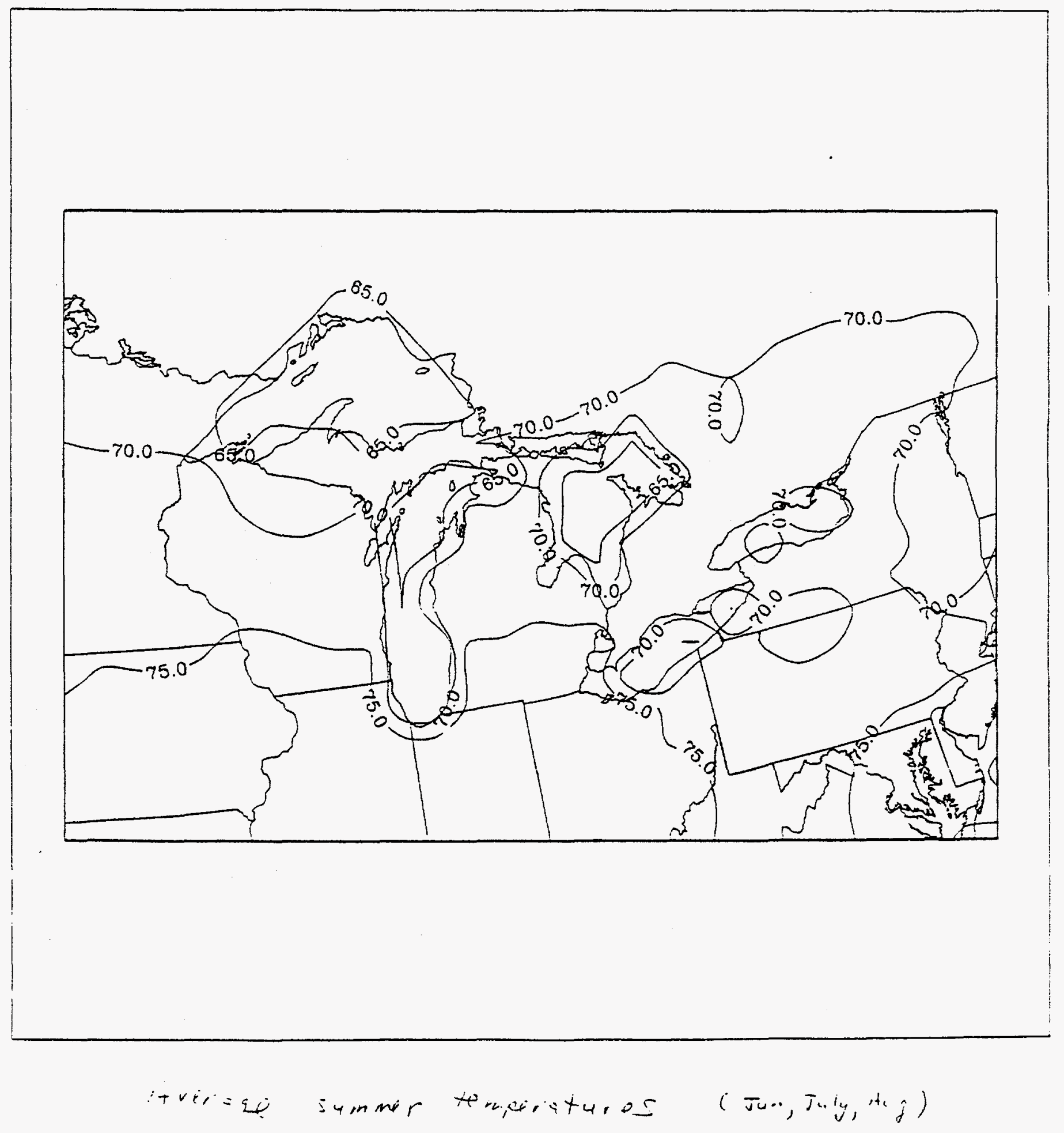




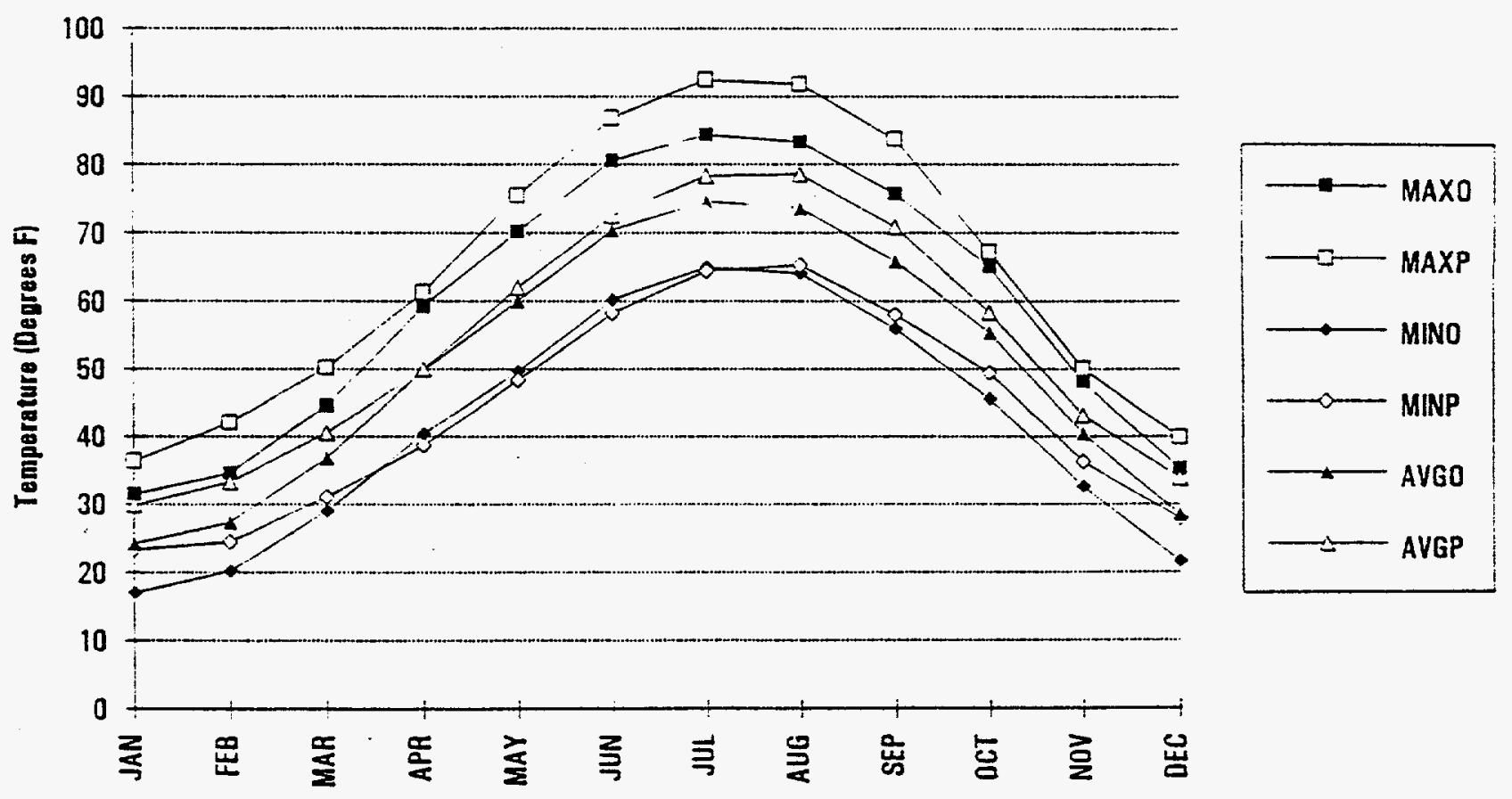




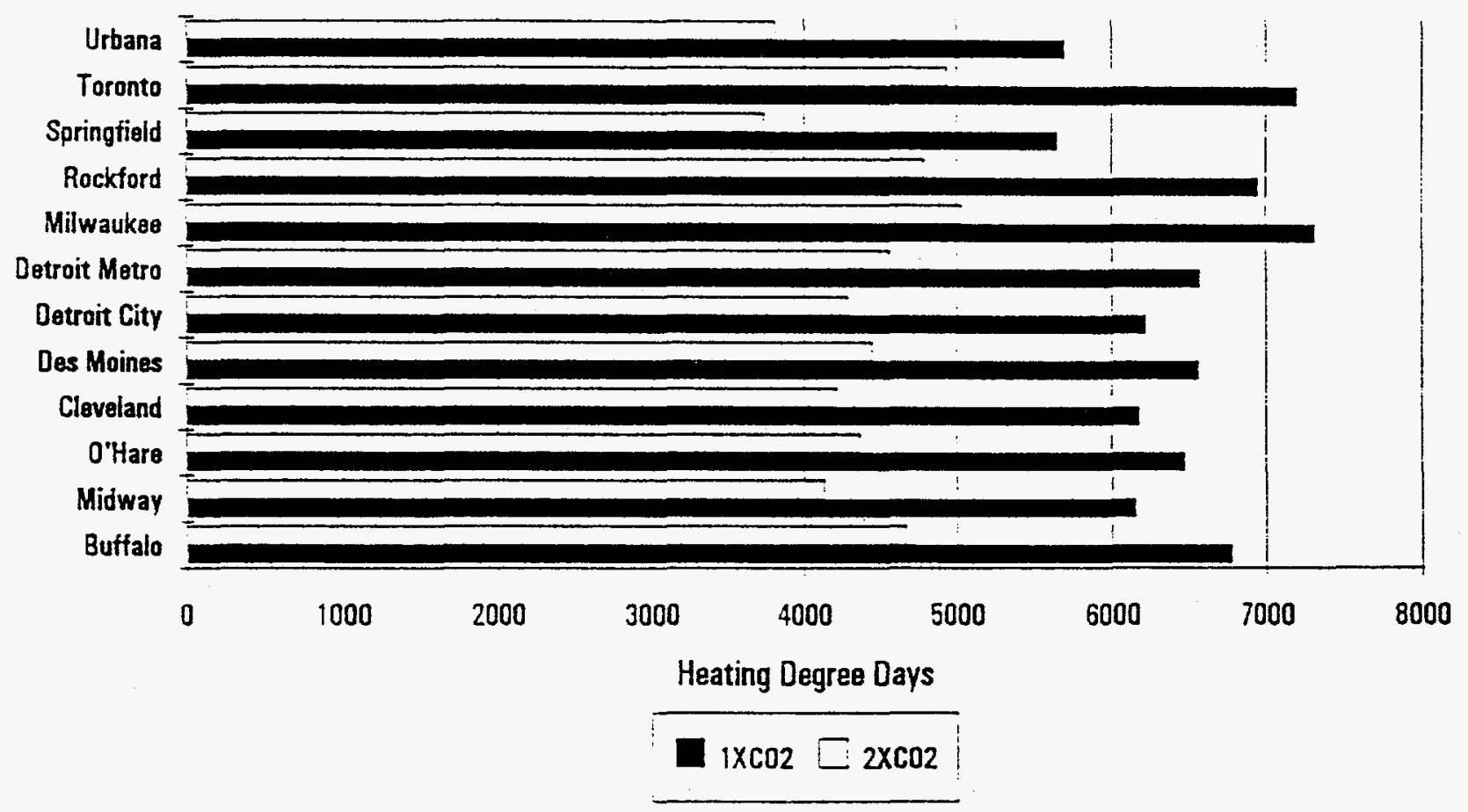




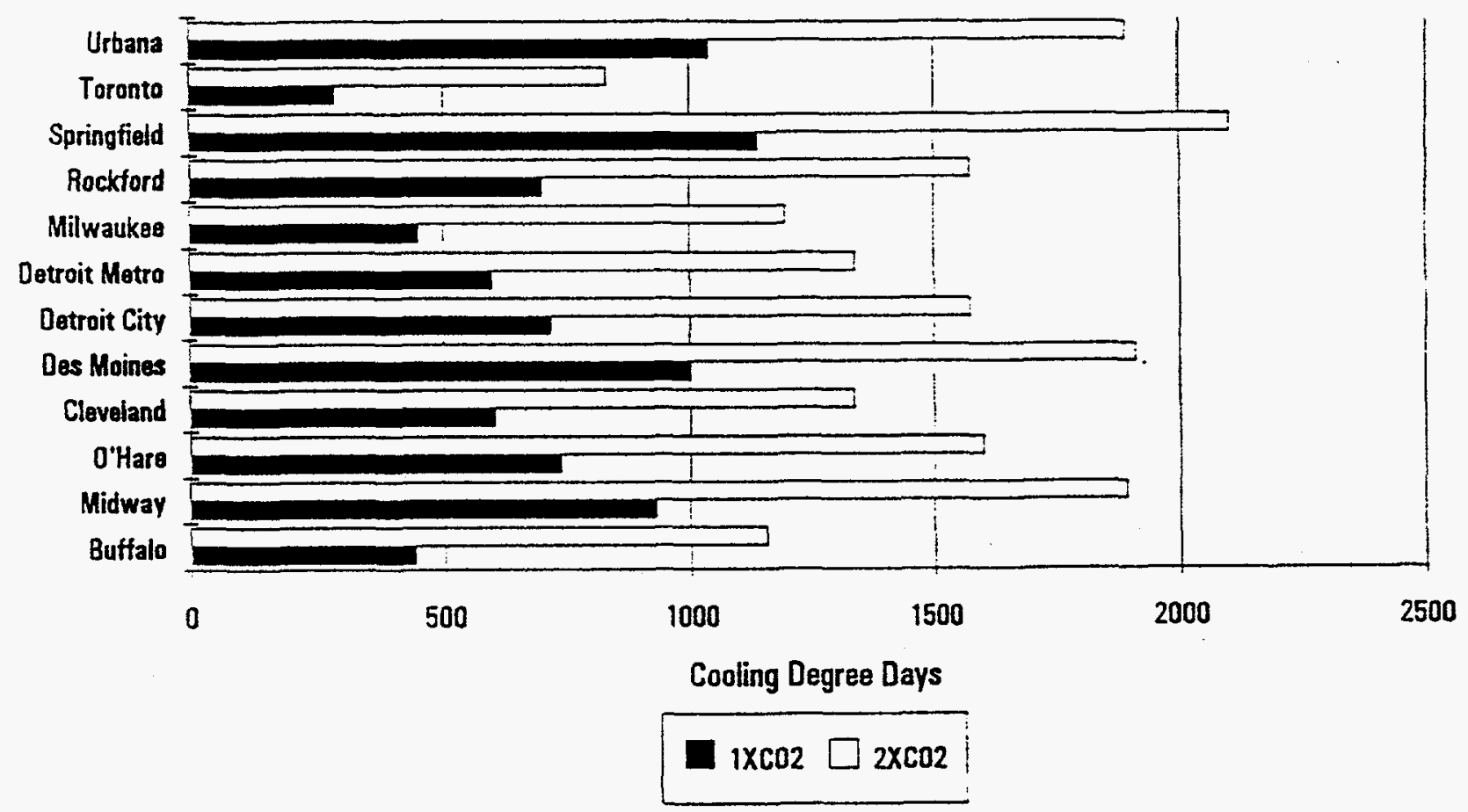

